\title{
2 Poems: An Accidental Ape, First Watch
}

\section{Roderick Marsh}

Roderick Marsh lives in Melbourne and occasionally moonlights as an ecological economist and management consultant. He also writes poetry-often in an apron. 


\section{An Accidental Ape}

Armed with finches and iguanas, Darwin And Wallace revealed a simple truth: Kalimantan's old man of the forest Is family. His auburn beard and piercing Eyes remind me of my Caledonian Forebears-a solitary pict, whose powerful Arms spin the world on its axis so we Can witness the vast tree bud again, in

Rwanda, where silverbacked cloud-forest Dwellers, abide in a deep meditation On digestion. Powerful chests spread over Broad bellies, they gesture to lower lands, where

The great river Congo splits love's Dominions from those of war-vicious gangs Roam the north, young warriors prove themselves By murdering unwary travellers In lopsided battles, ten against one; South of the river, young satyrs fence with Penis swords and caress buttocks as balm For wounded pride, while crotch-locked nymphs Rise to orgasmic crescendos.

We are north and south, made with rips and tears, Ecstatic rage, blood and death, tender pleasure too, Face-to-face, eyes joining with lips and tongue.

Wilberforce thought our simian ties an Insult; they terrified him by day, At night he dreamt a college of grinning Primates in purple socks leading him to Overlook the wild abyss where twin loops Of stardust spun down a kalpa, a dance For five elements; he woke, drenched, Divine order swamped by contingency. There was the vast topography-a Bestiary of earth, of air, and sea.

Greater in number were dead ends. A dread Came upon him, Man was absent almost Everywhere; no crown of creation, not Inevitable_-an accidental ape. 


\section{First Watch}

Begin when you can no longer see the lines on your palm held at arm's length. In summer, it is time when the black ants at your feet have melted into the dirt's twilight.

Forget your watch. Its sterile march cannot keep time held in sun, eye, body. Its stone heart and constant hands dissect the world, winding withered facets of cut certainty, flickering shadows behind glass.

Trust your eye, your calluses, the dirt under each fingernail, the beetle's stifled tickcarnal echoes to till the soil's hours as the earth spins seasons and settling blood washes wrongs away.

Begin when the black ants march across your swollen palms. Each carrying a small piece of the carrion beetle stuck in

your throat. 